\title{
Dinamik Basınç Sensörlerinin Kalibrasyonu İçin Referans Standard Geliştirilmesi
}

\author{
${ }^{1}$ Yasin Durgut, *2Recep Yılmaz, ${ }^{3}$ Bülent Aydemir, ${ }^{4}$ Eyup Bağc1 \\ 1,*2,3 Tübitak UME, Ulusal Metroloji Enstitüsü, Gebze-Kocaeli, Türkiye \\ ${ }^{4}$ Gemi Makineleri İşletme Mühendisliği Bölümü, Yıldız Teknik Üniversitesi, Türkiye
}

\section{Özet}

Dinamik basınç uygulamalarında, uygulanan basınç statik olmayıp zamanla değişen bir basınç olduğundan, dinamik basınç olarak adlandırılmaktadır. Bu tip sistemlerde yapılan çalışmalarda, basıncın dinamik olarak çok küçük zaman birimlerindeki değişiminin ve davranışının ortaya konulması gerekmektedir. Dinamik basınç sistemlerinde yapılan ölçümlerde, dinamik kalibrasyon ölçüm zinciri olarak adlandırabileceğimiz bir ölçüm düzeneği mevcut olup bu düzenek başlıca, dinamik basınç sensörü, sinyal şartlandırıcı ve yükselteci ile veri toplama birimlerinden oluşmaktadır. Bu çalışmada, dinamik basınç sensörlerinin kalibrasyonlarında kullanılmak üzere, serbest düşme prensibine göre çalışan dinamik referans basınç standardı geliştirilmesi konusunda gerçekleştirilen çalışmayla ilgili bilgiler verilmiştir.

Anahtar Kelimeler: Dinamik basınç sensörü, Dinamik basınç

\begin{abstract}
In dynamic pressure applications, it is called dynamic pressure since the applied pressure is not static but changes over time. In the studies carried out in such systems, it is necessary to demonstrate the change and behavior of pressure dynamically in very small time units. In the measurement of dynamic pressure systems, there is a measurement mechanism which can be called as dynamic calibration measurement chain which consists of dynamic pressure sensor, signal conditioner and amplifier and data collection units. In this study, information is given about the development of dynamic reference pressure standard which works according to free fall principle to be used in calibration of dynamic pressure sensors.
\end{abstract}

Key words: Dynamic pressure sensor, Dynamic pressure

*Sorumlu Yazar: Adres: Tübitak UME, Ulusal Metroloji Enstitüsü, Gebze-Kocaeli, Türkiye. E-mail adres: yilmaz.recep@tubitak.gov.tr, Telefon: +902626795000 


\section{Giriş}

Dinamik basınç sensörleri gerek ölçüm süreçlerinde gerekse kontrol süreçlerinde, havacılık, otomotiv, gıdaların işlenmesi [1, 2] gibi alanlar başta olmak üzere birçok alandaki uygulamalarda kullanılmaktadır. Bazı uygulamalar zamanla değişmeyen yani statik denilen karakteristiğe sahip olup belli tipteki basınç sensörleri zamanla değişmeyen söz konusu statik basıncı ölçmek amacıyla kullanılmaktadır. Ancak ilgili basınç değeri sabit bir değer olmayıp zamana bağlı olarak değişiklik gösteren bir büyüklüğe sahip ise bu şekildeki basınç "dinamik" olarak tanımlanmaktadır ve yapılan bir dinamik kalibrasyon sırasında kısa zaman aralığında basınç değerinde kayda değer değişiklik gösterir. Bir basınç sensörünün dinamik kalibrasyonu ya da dinamik basınç ölçümü, kalibrasyonu yapılan sensörün dinamik davranışının, sensörün kullanılacağı yerdeki ihtiyaç duyulan ölçüm doğruluğuna uygun şekilde dinamik davranışının ortaya konulmasını ve analizini içermektedir. Dinamik basınç kalibrasyonunda, referans dinamik basınç standardı tarafından kalibrasyonu yapılacak sensöre uygulanmak üzere değeri zamanla değişen güvenilir, kontrol edilebilir ve değeri iyi bilinen dinamik basınç üretilmelidir. Üretilen dinamik basınç değeri, test sensörü de denilen kalibre edilecek dinamik basınç sensörü için referans basınç değeri olarak kullanılmak üzere sensöre uygulanarak sensörün ürettiği basınç ya da elektriksel yük tepkisi ölçülmektedir.

\section{Dinamik Kalibrasyon Cihazının Çalışma Prensibi}

TUBITAK UME Ulusal Metroloji Enstitüsü, dinamik basınç sensörlerinin kalibrasyonarında referans standart olarak kullanılmak üzere, serbest düşen kütle prensibi ile çalışan referans standart geliştirmektedir. Cihaz enerjinin korunumu fizik yasasına göre çalışmakta olup, kütlenin potansiyel enerjisinden hareket enerjisi elde etmekte ve bu hareket enerjisinden de referans basınç oluşturulmaktadır. Sistemin çalışma prensibi Şekil 1'de verilmiştir. Kütle düşürmeli sistem, serbest düşme sırasında serbest düşen kütlenin kazandığ 1 hareket enerjisini, bir pistonun üzerine düşmek suretiyle aktarmaktadır ve piston aktarılan bu anlık kuvvette aynı hazneye bağlanmış olan test sensörlerine bu hazneyi dolduran akışkan tarafından iletilmektedir ve bu şekilde düşen kütlenin enerjisi kalibrasyonu yapılacak test sensörlerine ulaşmaktadır. Söz konusu sistem elemanları Şekil 1'de detaylı çizilmiştir. Ayrıca sistemin şematik görünümü de Şekil 2'de verilmiştir.

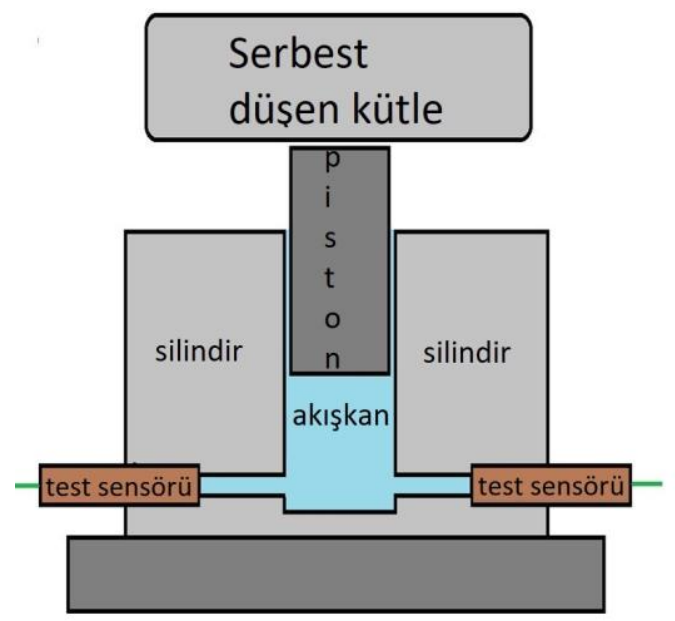

Şekil 1. Kütle düşürmeli sistemin genel çalışma prensibi 
Dinamik basınç kalibrasyon standardı, dinamik basınç ölçer sensörlerin kalibrasyonlarında kullanılmak üzere anlık pulse sinyalleri üretmek amacıyla kullanılmaktadır. Bu şekildeki bir kalibrasyonda kullanılan akışkanın cinsine bağlı olmak koşuluyla test sensörleri çıkışları yaklaşık (3-5) milisaniye genişliğinde yarı sinüs bir şekle sahip bir sinyal olmaktadır. Geliştirilen makinada oluşturulacak dinamik basıncın \%1 belirsizlikle $10 \mathrm{MPa}$ ile $500 \mathrm{MPa}$ basınç değerleri arasında olması hedeflenmektedir [1].

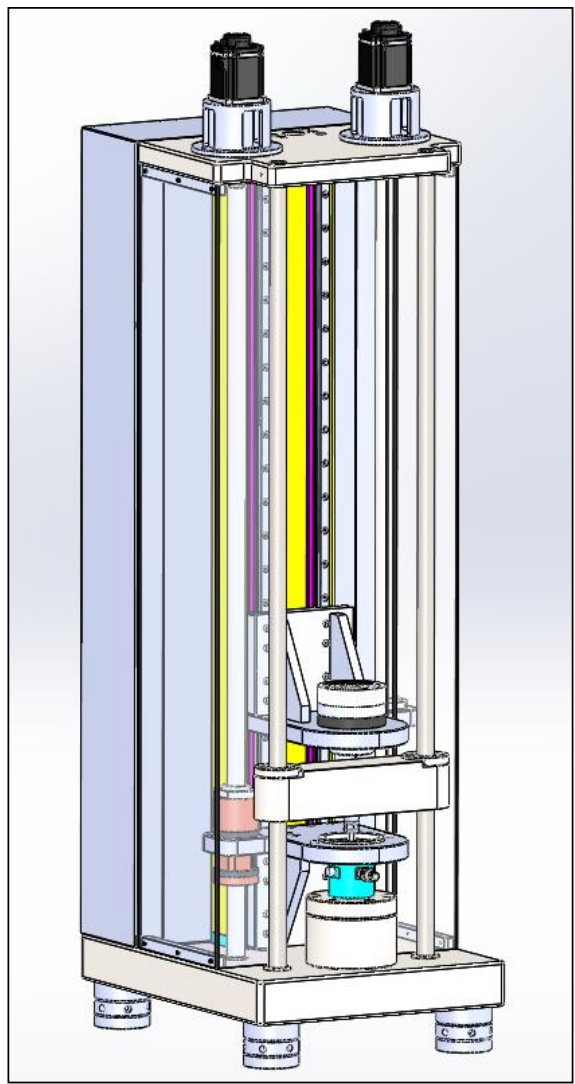

Şekil 2. Kütle düşürmeli sistemi şematik görünümü

Sistem kalibrasyon amacıyla kullanılmak üzere test basıncını, pistonun üzerine hızlıca düşen yataklanmış kütle ve pistonun da üzerine gelen bu etkiyi temas ettiği akışkana iletmesiyle üretir. Hidrolik akışkan içinde artan basınç birkaç yüz MPa değerine kadar ulaşmaktadır ve yüksek basınçlı dinamik test sensörlerinin hızlı ve doğru bir biçimde kalibre ve test edilmesini sağlar. Elde edilen enerji ve dolayısıyla basınç değeri, düşen kütlenin düşme yüksekliğinin değiştirilmesi ile değişmektedir ve ayarlanmaktadır [2].

Şekil 1'de çalışma prensibi anlatılan ve Şekil 2'de şematik görünümü verilen referans standardın Şekil 3'te üretimi ve montajı yapılmış hali görülmektedir. Makina üzerinde 2 farklı servo motor mevcuttur. Bir tanesi düşen kütleyi istenilen yüksekliğe çıkararak o noktadan serbest düşmeye bırakan elektromıknatısı hareket ettirirken diğer servo motor da düşen kütle pistona ilk defa çarptıktan sonra bozucu sinyal oluşturmasın diye kütlenin pistona tekrar çapmasını engelleyen tutucu sistemi hareket ettirmektedir. 


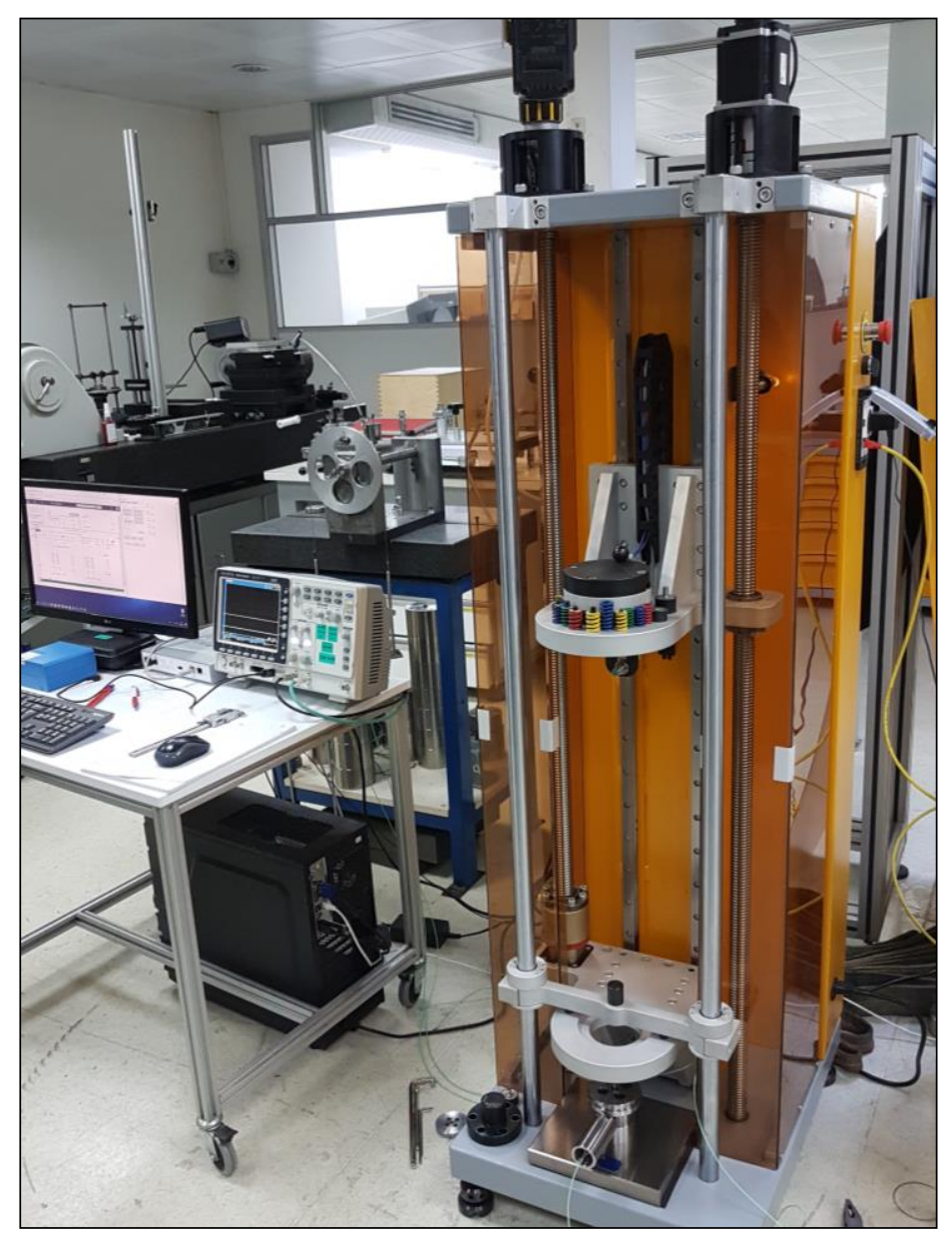

Şekil 3. Dinamik Kalibrasyon Sistemi

Dinamik basınç ölçüm sistemi farklı birimlerden oluşmaktadır. Başlıca üniteler arasında, motorların ve yataklanmış kütlenin ve mıknatısın bulunduğu gövde, piston ve test sensörlerinin bağlandığı içine basınç iletim akışkanının konulduğu başlık, interferometre ve buna bağlı veri toplama sistemi bulunmaktadır. Serbest düşen kütle yaklaşık 12 kilogram ağırlığındadır. İnterferometre lazer başlıkları gövdeye sabitlenmiş ve lazer 1şığının yansıtıldığ 1 retroreflektör, hareketli serbest düşen kütle üzerine sabitlenmiştir. İnterferometre serbest düşen kütlenin zamana karşı konum bilgisini ölçmekte ve buna bağlı veri toplama sistemi de düşen kütlenin ivmesini hesaplamaktadır. Bu bilgiler 1şı̆̆ında lazer tabanlı veri toplama sisteminin oluşturduğu net basınç toplam elde edilen kuvvetin pistonun alan değerine bölünmesiyle elde edilir. Serbest düşen kütle istenilen yüksekliğe bir elektromıknatıs kullanılarak çıkarılır. Düşme yüksekliği programlanabilir mantık kontrolcüsünün arayüzünde yazılan programdan girilir. Düşen kütle iki adet kılavuz çubuk ile yataklanır. $\mathrm{Bu}$ yataklama çubukları düşen kütlenin piston dikey çarpmasını sağlar ve tüm hareket enerjisi bu şekilde piston aktarılmış olunur. Ayrıca kütlenin yataklanmış olması serbest düşme deneyini her ölçüm için bir önceki ile aynı şartlarda oluşturmasını sağlamaktadır ve bu sayede tekrarlanabilir ölçümler alınabilmektedir. Sistemde bir süre ölçüm yaptıktan sonra, ölçüm başlığında yağ eksilmesi olursa piston altında bir miktar hava birikebilmektedir ve yağ ile piston arasına dolan bu hava da pistona çarpan kütlenin etkisini azaltarak hedeflenen basınç değerinin 
elde edilmesini engellemektedir. Böyle bir durumda ölçüm başlığına eksilen yağın tekrar ilave edilmesi gereklidir. Bu işlem için piston ya da sensörlerden bir tanesinin tamamen çıkarılması gerekli olup bu işlem zahmetli ve zaman kaybettiren bir işlem olmaktadır. Bu problemin çözümüne yönelik olarak ölçüm başlığı gövdesine ilave bir yağ haznesi eklenmiş ve ana başlıktan iğne vana ile ayrılmıştır. İğne vananın ortasında da çevirerek sıkıştırılan yivli küçük bir pompa düzeneği mevcuttur. İğne vana ve yivli yağ pompası Şekil 4.'te siyah renkte ve ölçüm başlı̆̆ da aynı şekil üzerinde mavi renkte görülmektedir. Ana ölçüm başlığında yağ eksildiği zaman iki hacmi ayıran iğne vana açılarak pompa çevrilmekte ve ana haznede eksilen yağ tamamen geri doldurulmaktadır. Sonra da tekrar iğne vana kapatılarak ölçümlere devam edilmektedir. Ölçüm başlığ1 ve yağ doldurma sistemi Şekil 4'te verilmiştir.

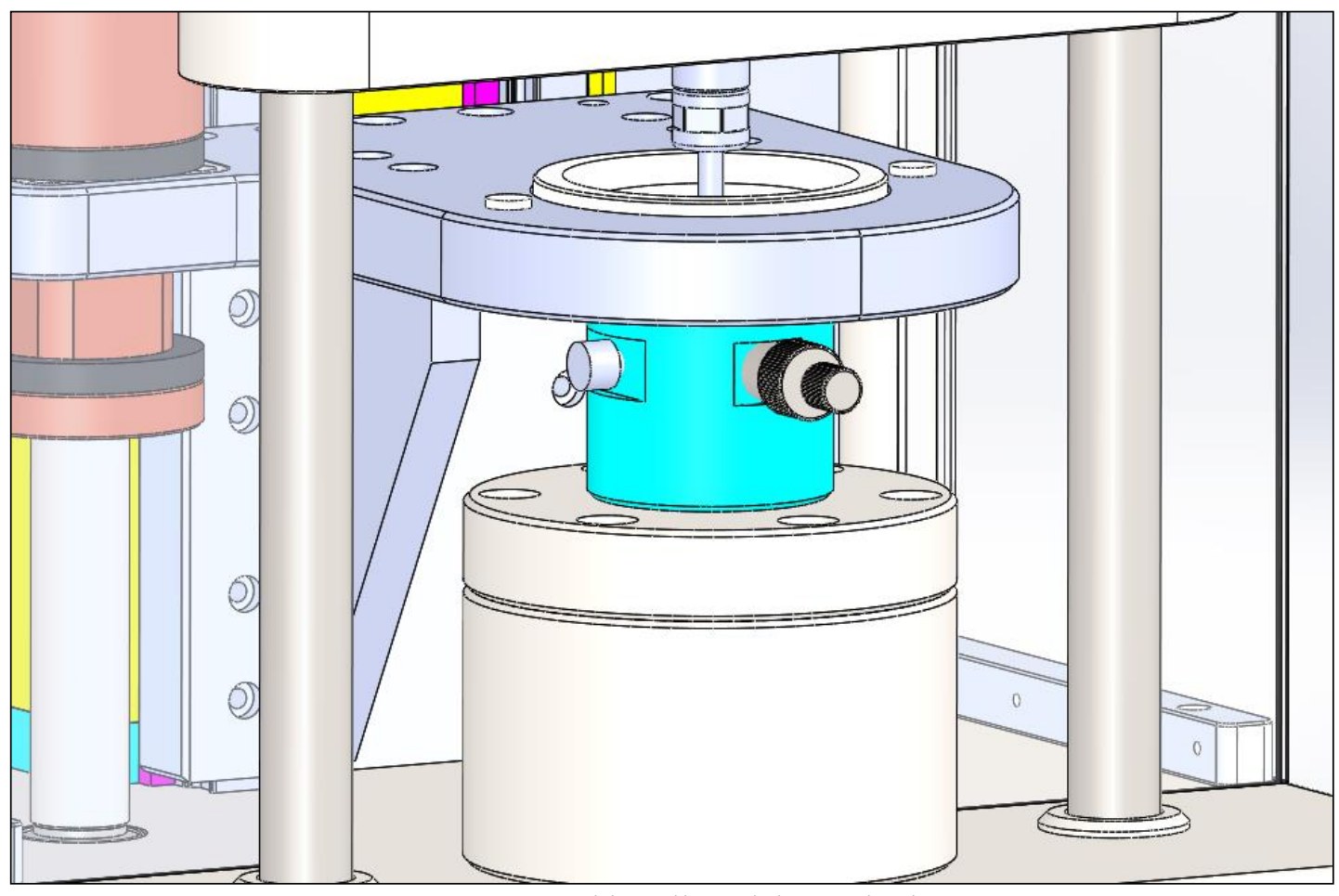

Şekil 4. Başlık ve ilave dolum ünitesi

Sistemin oluşturduğu referans basınç değeri, boyutsal ölçümler yardımıyla alanı oldukça hassas tespit edilmiş pistonun üzerine etki eden toplam kütlenin oluşturduğu kuvvetten hesaplanır. Piston alanı piston-silindir ünitesinin form (yuvarlaklık ve doğrusallık) ve mutlak çap ölçümleri kullanılarak boyutsal yaklaşımlarla hesaplanır. Buradaki toplam kütle, serbest düşen kütle, piston kütlesi ve piston ile beraber hareket eden akışkan kütlelerinin toplamına eşit olmaktadır. Toplam kütlenin ivmesi, statik o noktadaki yerçekimi ivmesi ile, lazer interferometreden ölçülen serbest düşen kütlenin şok ivmesinin toplamından oluşur [3]. Yataklanan serbest düşen kütlenin x-y ekseni etrafında oluşan dönme hareketi (pitch) ve dikey y ekseni etrafındaki dönme hareketi (yaw) etkileri, bu kütlenin ivme değerinin net olarak belirlenmesinde problemlere neden olabilmektedir. Bu etkilerin ortadan kaldırılması için 120'şer dereceyle kütle üzerine yerleştirilmiş 3 farklı lazer başlığg zamana karşı konum değişim bilgisini ölçmektedir. Lazer başlıkların bu amaçla kütle üzerine yerleşimi Şekil 5 'te verilmiştir. 


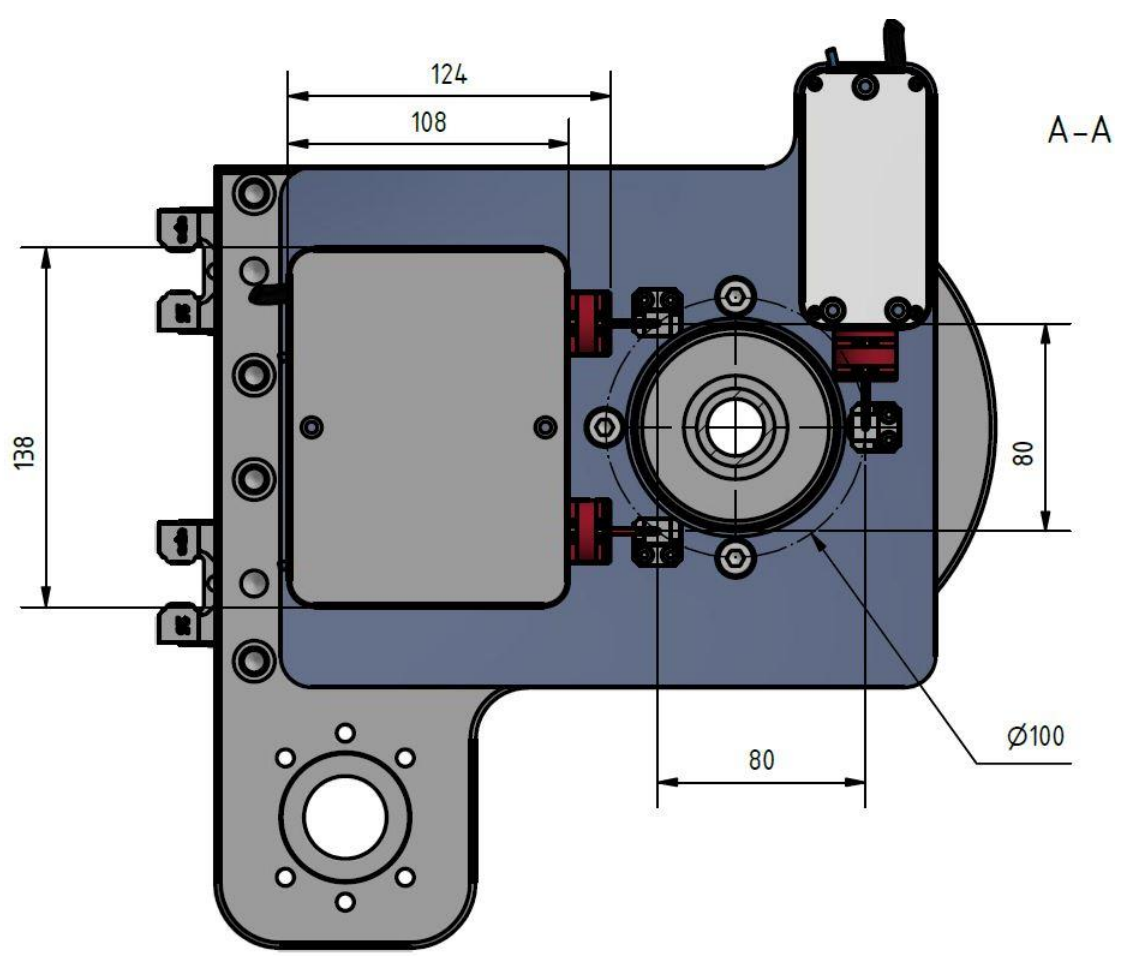

Şekil 5. Lazer başlıkların gövde üzerindeki yerleşimi

Elektromıknatısın ve dolayısıyla serbest düşen kütlenin kontrolü, 2 adet servo motor ve bunların da kontrolü programlanabilir mantık kontrolcüsüne ait arayüz de yazılan programlarla yapılmaktadır. Bu amaçla oluşturulmuş arayüz programı Şekil 6'da verilmiştir. Yazılan bu programda, düşen kütlenin düşme yükseklik bilgisi, serbest düşme hareketinin dolayısıyla ölçümün tekrar sayısı gibi bilgiler girilebilmektedir.

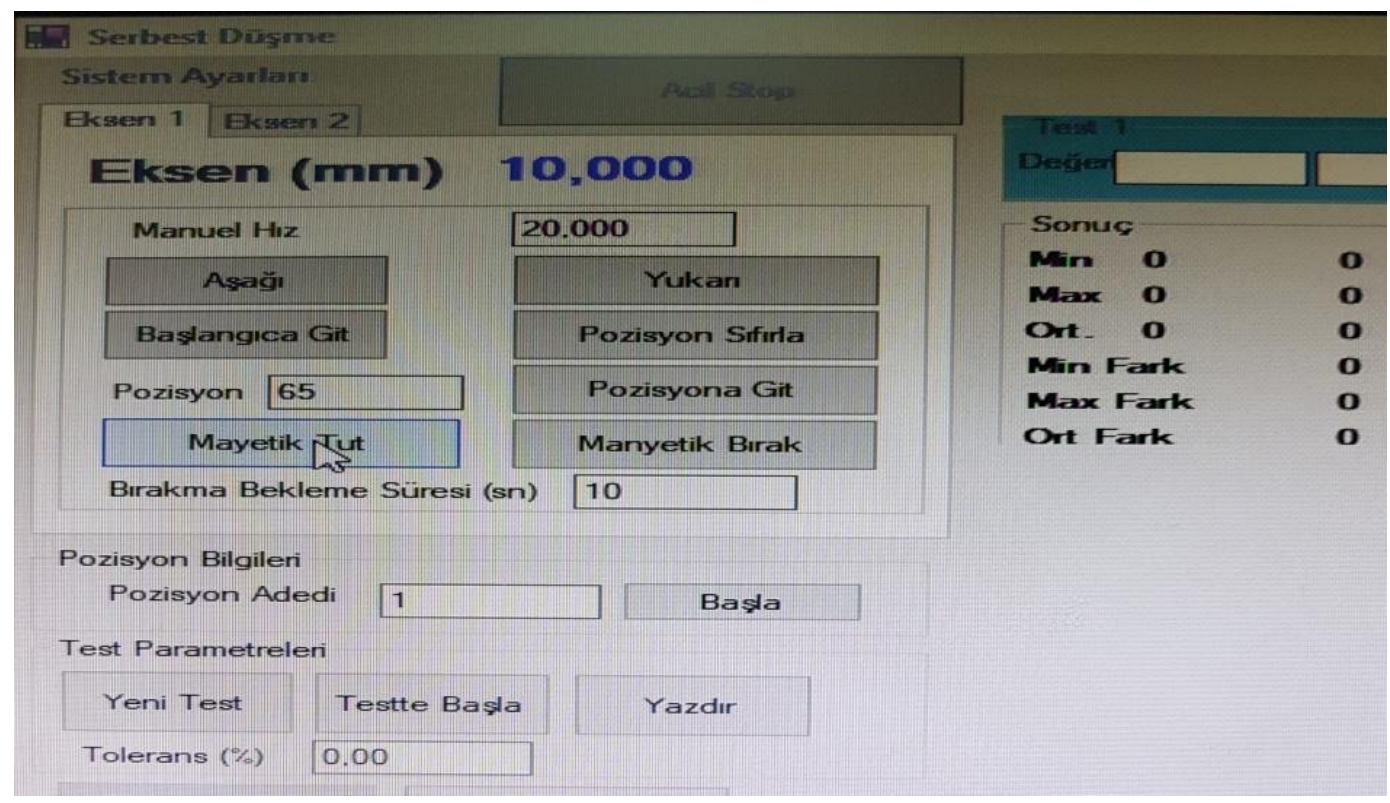

Şekil 6. Dinamik kalibrasyon sistemini kontrol eden arayüz yazılımı 
Her serbest düşme ölçümü öncesi, kütle elektromıknatıs tarafından alınarak pistona doğru aşağıya indirilir. Pistona dokunduğu anda gövde üzerine verilen zayıf akım elektrik devresi tamamlanmış olur. Elektrik devresinin tamamlanması etkisiyle PLC mıknatısı kontrol eden motorun hareketini durdurur. Sistem için serbest düşecek kütlenin piston dokunduğu bu nokta serbest düşme için referans sıfır noktası anlamına gelir. Atış yapılacak yükseklik sistem tarafından bu sıfır noktasından itibaren yukarı yönlü olarak ölçülür. Her seferinde ölçüm öncesi serbest düşecek kütle için referans sıfır noktasının tespiti, kütlenin hep aynı yükseklikten bırakılmasını sağlar ve bu durum da yapılan deneyin ölçüm sonuçlarının tekrarlanabilirliğinin iyileşmesine katkı sağlar.

\section{Performans Testi}

Sistemin performans testlerinin belirlenmesi amacıyla yapılan ölçümlerde Kistler tarafından üretilmiş 1053 kodlu mineral yağ kullanılmıştır. Piston düşen kütlenin tam altına gelecek biçimde kütlenin dikey ekseni doğrultusunda yerleştirilmiştir. Yağın ilettiği basınç etkisiyle test sensörleri tarafından üretilen yük çıkış değerleri fiber bir yük kablosu ile sinyal şartlandırıcıya iletilir. Sinyal şartlandırıcının 2 kanalı olup aynı anda 2 farklı test sensöründen gelen yük değerlerini şartlandırabilir. Sinyal şartlandırıcı olarak Kistler marka 6907B model cihaz kullanılmıştır. Ayrıca sinyal şartlandırıcı, analog çıkış bağlantıları da sağlamaktadır. Bu analog çıkış portları bir osiloskopa bağlanmıştır ve her 2 test sensörü tarafından üretilen basınç çıkış sinyalinin şeklini ve genliğini de bu şekilde gözleyebilmemiz mümkün olmaktadır. Test sensörü olarak $800 \mathrm{MPa}$ ölçüm kapasitesine sahip Kistler model 6213BK ve $500 \mathrm{MPa}$ ölçüm kapasitesine sahip Kistler model 6229AK piezoelektrik sensörleri kullanılmıştır. Ölçümler $50 \mathrm{MPa}, 100 \mathrm{MPa}$ ve $200 \mathrm{MPa}$ basınç noktalarında azalan basınç yönünde $5 \mathrm{kez}$ tekrarlanmak suretiyle yapılmıştır. Ölçüm sonuçları Tablo 1'de verilmiştir.

Tablo 1. Farklı basınç değerleri için deneysel ölçüm sonuçları

\begin{tabular}{|c|c|c|}
\hline Nominal basınç (bar) & Ölçülen Pressure (bar) & Tekrarlanabilirlik (\%) \\
\hline \multirow{5}{*}{2000} & 1990 & \multirow{5}{*}{0.50} \\
\hline & 1980 & \\
\hline & 1990 & \\
\hline & 1980 & \\
\hline & 1990 & \\
\hline \multirow{5}{*}{1000} & 1000 & \multirow{5}{*}{1.00} \\
\hline & 1000 & \\
\hline & 995 & \\
\hline & 1005 & \\
\hline & 1000 & \\
\hline \multirow{5}{*}{500} & 505 & \multirow{5}{*}{1.00} \\
\hline & 505 & \\
\hline & 500 & \\
\hline & 500 & \\
\hline & 505 & \\
\hline
\end{tabular}


Sensör çıkış sinyalleri yarım sinüs dalga şekli göstermektedir. Yaklaşık periyodu 5 milisaniye civarındadır. Sinyalin genliği de 1 bar basınç için 1 mili volt olarak elde edilmektedir. Sarı ve mavi sinyaller her iki test sensörü çıkış sinyalidir. Sensör çıkış sinyalleri Şekil 7'de verilmiştir.
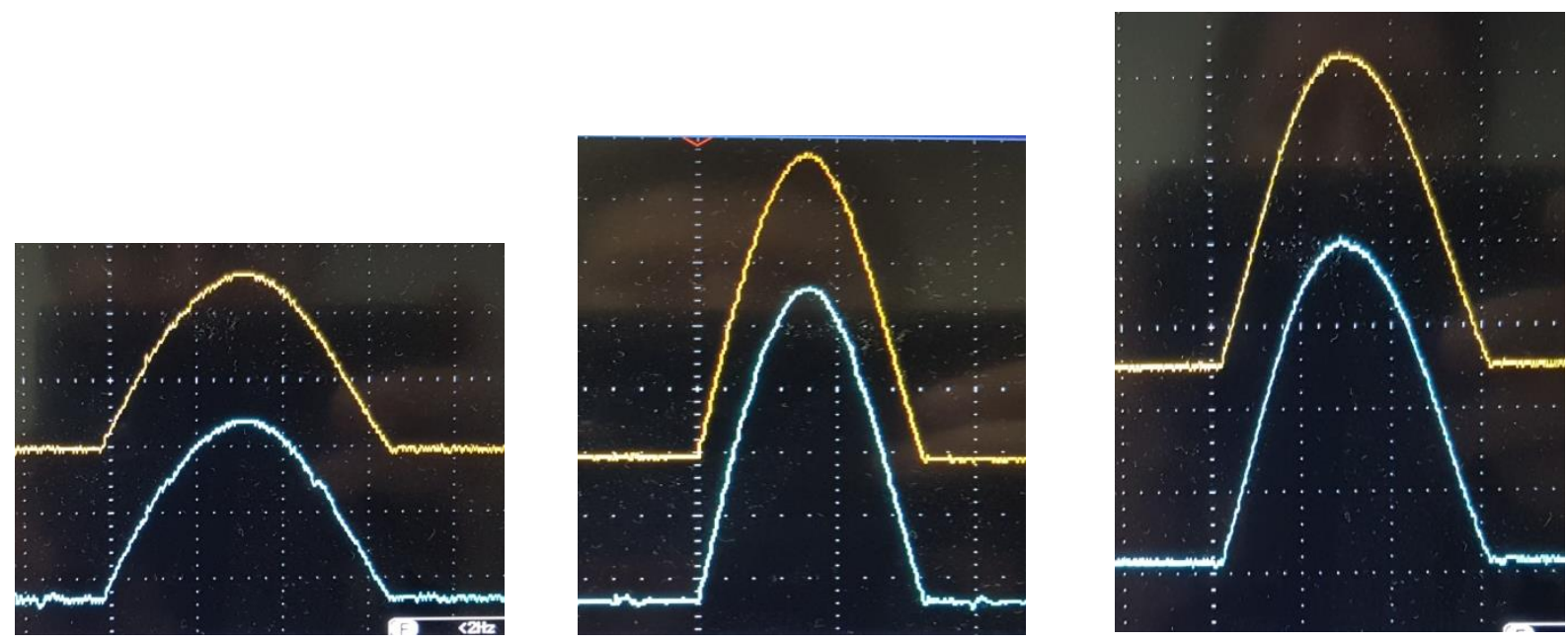

Şekil 7. 50 MPa, 100 MPa ve 200 MPa basınç değerleri için sensörlerin analog çıkış sinyalleri

\section{Sonuç}

Bu çalışmada, yeni tasarlanmış olunan dinamik basınç sensörlerinin kalibrasyonlarının yapılması amacıyla kullanılan kütle düşürmeli dinamik basınç standardının tasarımı ve yapılan çalışmalar anlatılmıştır. Sistemi oluşturan bileşenler hakkında bilgiler verilmiş ve sistem üzerinde yapılan örnek bir ölçümün sonuçları sunulmuştur. Sistemin yapısında yer alan alt birimler ve çalışma prensibi açıklanmıştır. Sistemin performans test sonuçları da Tablo 1'de verilmiştir. Dinamik kalibrasyon sisteminin performans test sonuçlarına göre ölçümlerin tekrarlanabilirlik [1] değeri \%1'den daha küçük olarak bulunmuştur. Bu sonuçlar, bu sistemin dinamik sensörlerin kalibrasyonlarının yapılması amacıyla kullanılabileceği, cihaz tasarım aşamasında belirlenen doğruluk hedefine ulaşılmak suretiyle görülmüş olunmaktadır.

\section{Kaynaklar}

[1] Bilgiç E., B. Durgut Y., Acta Phys. Pol. A, 128, B-267, (2015)

[2] Durgut Y., Bağc1 E., Akşahin E., İnce A. T., Braz J. Soc. Mech. Sci. Eng., 39, 3645-3655, (2017)

[3] Salminen J., Högström R., Saxholm S., Lakka A., Riski K., Heinonen M. Metrologia, 55, 52$59,(2018)$

[4] Durgut Y., Bilgiç E., Akşahin E., Fank S., Bağcı E., İnce A. T., Aydemir B. EJOSAT, 8, 4649, (2016) 